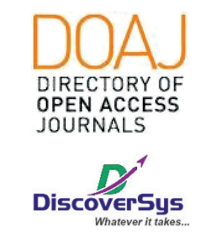

Published by DiscoverSys

\section{Hasil tajam pengelihatan pasca operasi katarak senilis di RSUP Sanglah Denpasar periode Oktober 2016 - Juni 2017}

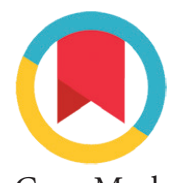

CrossMark

\author{
Anak Agung Gde Arisena Asmara, ${ }^{1 *}$ Putu Budhiastra, ${ }^{2}$ Ni Ketut Niti Susila ${ }^{2}$
}

\section{ABSTRACT}

Introduction: Cataract is a type of eye disease that occurs in the lens of the eye. Cataract occurs not only due to the age factor, but also can occur in children born with these conditions or congenital factors. This study aimed to find out visual acuity outcome after senile cataract surgery at RSUP Sanglah Denpasar on October 2016 - June 2017 period. Method: The type of this research was descriptive cross-sectional conducted at RSUP of Sanglah Denpasar using the medical records of the period of October 2016 - June 2017. The sampling technique used the total sampling, with the number of samples of 32 subjects. The result of this research was processed by using a computer software.

Result: The postoperative patients with poor outcome tended to be experienced by the senile cataract of mature group compared to the immature that was around $9.1 \%$, borderline outcome tended to be experienced by group with immature senile cataract of 23.8\% while the dominant senile cataract outcome was $81.8 \%$. Patients undergoing SICS procedures tended to have a poor outcome compared to those undergoing a phacoemulsification procedure of $16.7 \%$. Borderline outcome tended to the group undergoing phacoemulsification procedures, and $83.3 \%$ of the good outcome tended to be experienced by the group undergoing SICS procedures.

Conclusion: This research concludes that good outcome come from cataract senile mature group (81.8\%) and the group that doing SICS procedure (83.3\%)

Keywords: Cataract, Post-Operation, Outcome

Cite This Article: Asmara, A.A.G.A., Budhiastra, P., Susila, N.K.N. 2019. Hasil tajam pengelihatan pasca operasi katarak senilis di RSUP Sanglah Denpasar periode Oktober 2016 - Juni 2017. Intisari Sains Medis 10(2): 263-267. D0I: 10.15562/ism.v10i2.187

\title{
ABSTRAK
}

Latar Belakang: Katarak adalah suatu jenis penyakit mata yang terjadi pada lensa mata. katarak terjadi karena faktor usia, namun juga dapat terjadi pada anak-anak yang lahir dengan kondisi tersebut atau faktor bawaan. Tujuan penelitian ini adalah untuk mengetahui hasil tajam pengelihatan pasien katarak senilis pasca operasi di RSUP Sanglah Oktober 2016 - Juni 2017.

Metode: Jenis penelitian ini adalah penelitian deskriptif crossectional yang dilaksanakan di RSUP Sanglah Denpasar menggunakan catatan rekam medis periode Oktober 2016 - Juni 2017. Teknik pengambilan sampel menggunakan total sampling, dengan jumlah sampel sebanyak 32 subjek. Hasil penelitian ini diolah dengan menggunakan software komputer.

Hasil: Pasien pasca operasi yang memiliki poor outcome cenderung dialami oleh kelompok katarak senilities matur dibandingkan dengan yang imatur yaitu berkisar 9,1\%, borderline outcome cenderung dialami oleh kelompok dengan katarak senilis imatur yaitu 23,8\% sedangkan good outcome dominan pada katarak senilis matur yaitu $81,8 \%$. Pada pasien yang menjalani prosedur SICS cendrung memiliki poor outcome dibandingkan dengan yang menjalani prosedur phacoemulsification yaitu 16,7\%, borderline outcome cenderung pada kelompok yang menjalani prosedur phacoemulsification, dan good outcome sebesar $83,3 \%$ cendrung dialami oleh kelompok yang menjalani prosedur SICS.

Simpulan: Penelitian ini menyimpulkan bahwa good outcome terbanyak pada kelompok dengan katarak senilis mature $(81,8 \%)$ dan kelompok yang menjalani prosedur SICS (83,3\%).
${ }^{2}$ Bagian/SMF IImu Kesehatan Mata, Fakultas Kedokteran Universitas Udayana-RSUP Sanglah Denpasar

${ }^{*}$ Correspondence to: Anak Agung Gde Arisena Asmara, Program Studi Pendidikan Dokter Fakultas Kedokteran Universitas Udayana

agung_arisena@yahoo.com

Diterima: 29-03-2018

Disetujui: 28-04-2018

Diterbitkan: 01-08-2019
Kata kunci : katarak, pasca operasi, outcome

Cite Pasal Ini: Asmara, A.A.G.A., Budhiastra, P., Susila, N.K.N. 2019. Hasil tajam pengelihatan pasca operasi katarak senilis di RSUP Sanglah Denpasar periode Oktober 2016 - Juni 2017. Intisari Sains Medis 10(2): 263-267. D0I: 10.15562/ism.v10i2.187

\section{PENDAHULUAN}

Katarak adalah suatu jenis penyakit mata yang terjadi pada lensa mata. Katarak merupakan kekeruhan pada lensa yang dapat terjadi akibat hidrasi lensa, sehingga sinar yang masuk terhalang. Katarak terjadi karena faktor usia, namun juga dapat terjadi pada anak-anak yang lahir dengan kondisi tersebut atau faktor bawaan. Katarak juga dapat terjadi setelah trauma, inflamasi, atau penyakit lainnya. ${ }^{1}$ 
Katarak senilis merupakan kekeruhan lensa mata yang terjadi karena faktor usia. Gangguan ini ditandai dengan adanya peneban progresif secara bertahap dari lensa mata. Katarak senilis merupakan salah satu penyebab utama gangguan penglihatan dan kebutaan di dunia. ${ }^{1}$

Sedikitnya 5 sampai 10 juta pasien memiliki gangguanpenglihatan katarak setiap tahunnya dengan metode teknik bedah modern menghasilkan 100.000 sampai 200.000 buta mata. ${ }^{2}$ Katarak senilis merupakan penyebab utama gangguan penglihatan pad orang tua.

Katarak senilis dapat dikategorikan menjadi 3 jenis pada pathogenesis yaitu katarak nuklear, katarak kortikal, dan katarak subkapsularis posterior. Pada diagnosis katarak senilis dibagi lagi menjadi 4 jenis stadium yaitu katarak insipien, katarak imatur, katarak matur, dan katarak hipermatur. ${ }^{1}$

Beberapa tahun terakhir bermacam-macam teknik operasi telah dikembangkan daritulisan teknik kuno sampaiteknik terbaru fakoemulsifikasi. Ada 4 jenis terapi katarak senilis yaitu intracapsular catarak extraction atau ICCE, extracapsular cataract extraction atau ECCE, Phacoemulsification atau fakoemulsifikasi, dan small incision cataract surgery atau SICS). ${ }^{3}$ Hasil tajam penglihatan atau visus pasca operasi katarak senilis dapat dibagi menjadi 4 kriteria yaitu good outcome, bordeline outcome, poor outcome, dan suboptimal outcome.,12

Untuk saat ini terapi fakoemulsifikasi memberikan prognosis penglihatan yang sangat menjanjikan mencapai sekurangnya 2 baris snellen chart. SICS juga dapat dijadikan pilihan terapi yang hampir sama tingkat keberhasilannya dengan fakoemulsifikasi. ${ }^{1}$ Berdasarkan ulasan diatas, penulis tertarik untuk melakukan penelitian mengenai hasil tajam penglihatan pasca operasi katarak senilis di RSUP Sanglah.

\section{METODE}

Penelitian ini menggunakan rancangan deskriptif corss-sectional, yang melakukan evaluasi hasil tajam pengelihatan pasca operasi bedah katarak senilis di RSUP Sanglah periode Oktober 2016 Juni 2017. Penelitian ini menggunakan data rekam medis seluruh pasien katarak senilis yang menjalani operasi bedah katarak di RSUP Sanglah Denpasar pada periode penelitian. Analisis data dilakukan menggunakan perangkat lunak SPSS version 21.0 kemudian data dijabarkan dalam bentuk tabel. Hasil tajam pengelihatan pada penelitian ini dikelompokkan menjadi tiga kategori yaitu good outcome (visus $>6 / 18$ ), borderline outcome (visus <6/18-6/60), dan poor outcome (visus $<6 / 60$ ).

\section{HASIL}

Penelitian ini menggunakan 32 data subjek penelitian yang didapatkan melalui data rekam medis pasien RSUP Sanglah, kemudian akan dipaparkan secara deskriptif mengenai karakteristik dari subjek penelitian dan outcome dari operasi katarak serta jenis operasi yang dilalui oleh subjek penelitian. Karakterisrik subjek meliputi usia, jenis kelamin, asal, pekerjaan, pendidikan, grade, jenis operasi, dan outcome pengelihatan yang disajikan pada tabel 1 .

Berdasarkan tabel 1, dapat diketahui bahwa rerata usia pada sampel penelitian ini adalah 64 tahun,kelompok usia 51-60 tahun dengan proporsi 40,6\%, kelompok usia 61-70 tahun dengan proporsi $34,4 \%$, kelompok usia 71-80 tahun dengan proporsi $18,8 \%$, dan kelompok usia $>80$ tahun dengan proporsi $6,3 \%$. Berdasarkan jenis kelamin, laki-laki lebih banyak dibandingkan dengan perempuan yaitu dengan proporsi $78,1 \%$. Berdasarkan tingkat pendidikan, tingkat pendidikan tinggi lebih banyak dibandingkan dengan tingkat pendidikan rendah yaitu dengan proporsi $71,9 \%$. Berdasarkan asal sampel penelitian, sampel yang berasal dari desa lebih banyak dibandingkan dengan sampel yang berasal dari desa yaitu dengan proporsi $65,6 \%$. Berdasarkan pekerjaan, sampel penelitian antara yang bekerja dan tidak bekerja memiliki proporsi yang sama yaitu $50 \%$. Berdasarkan stadium katarak, sampel penelitian yang mengalami katarak senilis imatur lebih banyak dibandingkan dengan sampel yang mengalami katarak senilis matur yaitu dengan proporsi $65,6 \%$. Berdasarkan jenis operasi yang dilalui sampel, metode phacoemulsification lebih banyak digunakan dibandingkan dengan metode SICS yaitu dengan proporsi $81,3 \%$. Berdasarkan outcome operasi, sampel dengan good outcome lebih banyak dibandingkan dengan poor outcome dan borderline outcome yaitu dengan proporsi $78,1 \%$. Berikut akan dipaparkan gambaran outcome (poor, borderline, good) berdasarkan stadium katarak yang dialami dan jenis operasi oleh sampel penelitian yang disajikan pada tabel 2.

Berdasarkan tabel 2, dapat diketahui bahwa poor outcome cenderung dialami oleh kelompok subjek dengan katarak senilis matur dibandingkan dengan katarak senilis imatur yaitu dengan proporsi $9,1 \%$, borderline outcome cenderung dialami oleh kelompok subjek dengan katarak senilis imatur dibandingkan dengan katarak senilis matur yaitu dengan proporsi $23,8 \%$, sedangkan good outcome cenderung dialami oleh kelompok dengan katarak senilis matur dibandingkan dengan katarak senilis imatur yaitu dengan proporsi $81,8 \%$.

Berdasarkan tabel 2, dapat diketahui bahwa poor outcome cenderung dialami oleh kelompok subjek yang menjalani prosedur SICS dibandingkan 
Tabel 1 Karakteristik Subjek

\begin{tabular}{|c|c|c|}
\hline Karakteristik & Jumlah (n = 32) & Persentase (\%) \\
\hline Usia $($ Mean \pm SD) & $64.03 \pm 9.42$ & $100 \%$ \\
\hline 51-60 tahun & 13 & $40,6 \%$ \\
\hline $61-70$ tahun & 11 & $34,4 \%$ \\
\hline $71-80$ tahun & 6 & $18,8 \%$ \\
\hline$>80$ tahun & 2 & $6,3 \%$ \\
\hline \multicolumn{3}{|l|}{ Jenis Kelamin } \\
\hline Laki-laki & 25 & $78,1 \%$ \\
\hline Perempuan & 7 & $21,9 \%$ \\
\hline \multicolumn{3}{|l|}{ Tingkat Pendidikan } \\
\hline Pendidikan Tinggi & 23 & $71,9 \%$ \\
\hline Pendidikan Rendah & 9 & $28,1 \%$ \\
\hline \multicolumn{3}{|l|}{ Asal } \\
\hline Kota & 11 & $34,4 \%$ \\
\hline Desa & 21 & $65,6 \%$ \\
\hline \multicolumn{3}{|l|}{ Pekerjaan } \\
\hline Bekerja & 16 & $50 \%$ \\
\hline Tidak Bekerja & 16 & $50 \%$ \\
\hline \multicolumn{3}{|l|}{ Stadium } \\
\hline Katarak Senilis Imature & 21 & $65,6 \%$ \\
\hline Katarak Senilis Mature & 11 & $34,4 \%$ \\
\hline \multicolumn{3}{|l|}{ Jenis Operasi } \\
\hline Phacoemulsification & 26 & $81,3 \%$ \\
\hline Small Insicion Catarac Surgery (SICS & 6 & $18,8 \%$ \\
\hline \multicolumn{3}{|l|}{ Outcome operasi } \\
\hline Poor outcome & 1 & $3,1 \%$ \\
\hline Borderline outcome & 6 & $18,8 \%$ \\
\hline Good outcome & 25 & $78,1 \%$ \\
\hline
\end{tabular}

Tabel 2 Gambaran outcome berdasarkan stadium katarak dan jenis operasi

\begin{tabular}{lcccc}
\hline & \multicolumn{3}{c}{ Outcome (N, \%) } & \multirow{2}{*}{ Jumlah (N, \%) } \\
\cline { 2 - 4 } Karakteristik & Poor & Borderline & Good & \\
\hline $\begin{array}{l}\text { Stadium Katarak } \\
\text { Katarak Senilis Matur }\end{array}$ & $1(9,1 \%)$ & $1(9,1 \%)$ & $9(81,8 \%)$ & $11(100 \%)$ \\
$\quad$ Katarak Senilis Imatur & $0(0 \%)$ & $5(23,8 \%)$ & $16(76,2 \%)$ & $21(100 \%)$ \\
$\begin{array}{l}\text { Jenis Operasi } \\
\text { Phacoemulsification } \\
\text { SICS }\end{array}$ & $0(0 \%)$ & $6(23,1 \%)$ & $20(76,9 \%)$ & $26(100 \%)$ \\
\hline
\end{tabular}

dengan phacoemulsification yaitu dengan proporsi $16,7 \%$, sedangkan borderline outcome cenderung dialami oleh kelompok subjek yang menjalani prosedur phacoemulsification dibandingkan dengan SICS yaitu dengan proporsi 23,1\%, sedangkan good outcome cenderung dialami oleh kelompok yang menjalani prosedur SICS dibandingkan dengan phacoemulsification yaitu dengan proporsi $83,3 \%$.

\section{PEMBAHASAN}

Hasil penelitian menemukan rerata usia pada pasien katarak adalah 64 tahun. Penelitian lain oleh Claudia 
(2017) mengenai survival katarak dalam 30 tahun, menemukan bahwa kasus katarak pada usia 45-64 tahun dengan proporsi 9,07\%, usia 65-69 tahun dengan proporsi 9,73\%, usia 70-74 tahun dengan proporsi $16,23 \%$, usia $75-79$ tahun dengan proporsi 24,19\%. Temuan ini juga menemukan bahwa katarak memiliki kecendrungan untuk lebih sering terjadi seiiring dengan peningkatan usia. ${ }^{5}$

Berdasarkan jenis kelamin, laki-laki lebih banyak dibandingkan dengan perempuan yaitu dengan proporsi 78,1\%. Studi lain oleh Salomao (2009) mengenai prevalensi dan outcome operasi katarak di brazil menemukan bahwa jenis kelamin perempuan lebih banyak mengalami katarak yaitu dengan proporsi 58\%, temuan ini merupakan temuan yang bertolak belakang dengan yang ditemukan. ${ }^{6}$

Suatu ulasan mengenai epidemiologi dan faktor resiko terkait dengan katrak senilis oleh Sheila (1995) menyatakan jenis kelamin perempuan memiliki suatu resiko yang sedikit lebih besar mengalami katarak dibandingkan dengan laki-laki, yang diduga oleh karena adanya peranan hormonal yang berhenti pada fase menopause yang menyebabkan terjadinya fenomena tersebut. ${ }^{7}$

Berdasarkan stadium katarak, sampel penelitian yang mengalami katarak senilis imatur lebih banyak dibandingkan dengan sampel yang mengalami katarak senilis matur yaitu dengan proporsi $65.6 \%$. Penelitian yang dilakukan oleh Hussain dkk (2005) mengenai prevalensi katarak pada daerah pinggiran Indonesia, studi ini menemukan tingkat kekeruhan katarak yang semakin tinggi seiring dengan peningkatan usia. Pada penelitian ini usia yang lebih banyak adalah kelompok usia 45-64 tahun, sehingga kemungkinan hal ini yang mendasari suatu keadaan adanya katarak senilis imatur yang lebih banyak dibandingkan dengan katarak senilis matur. ${ }^{8}$

Berdasarkan jenis operasi yang dilalui sampel, metode phacoemulsification lebih banyak digunakan dibandingkan dengan metode SICS yaitu dengan proporsi 81,3\%. Phacoemulsification merupakan suatu prosedur pilihan dalam operasi katarak. Teknik ini melalui suatu prosedur pembukaan terhadap bagian anterior dari kapsula lensa, kemudian lensa di lakukan emulsifikasi menggunakan gelombang ultrasonic dan kemudian dilakukan aspirasi melalui insisi yang telah dilakukan. Dibandingkan dengan suatu ekstraksi katarak ekstrakapsular, teknik ini memungkinkan adanya insisi yang lebih kecil sehingga menyebabkan proses rehabilitasi yang lebih baik. Selain itu teknik ini menurunkan adanya komplikasi bedah seperti keadaan bilik mata depan yang dangkal pada saat intra operatif, prolapse iris, dan astigmatisme post operatif. ${ }^{9}$ Studi lain yang dilakukan oleh Gogate (2007) mengenai perbandingan penggunaan phacoemulsifikasi dengan teknik SICS di India, menemukan bahwa metode Phacoemulsifikasi lebih sering digunakan dibandingkan dengan metode SICS yaitu dengan proprosi 53\%. ${ }^{10}$

Penelitian lain yang dilakukan oleh Venkatesh (2010) mengenai perbandingan teknik phacoemulsification dan SICS pada katarak, terhadap 133 subjek yang menjalani prosedur phacoemulsification dan 137 subjek yang menjalani prosedur SICS. Visus pasca operasi $<2 / 200$ (poor outcome) cenderung lebih banyak terjadi pada kelompok subjek yang menjalani prosedur SICS yaitu dengan proporsi $1,7 \%$, sedangkan perbaikan visus 20/20 20/30 cenderung lebih banyak pada kelompok yang menjalani suatu prosedur phacoemulsification yaitu dengan proporsi 45,1\%. Penelitian tersebut menyatakan tidak terdapat perbedaan yang bermakna pada kedua prosedur tersebut, namun pada kelompok yang menjalani prosedur phacoemulsification memiliki tajam UDVA (Uncorrected distance visual acuity) yang sedikit lebih baik dibandingkan dengan kelompok yang menjalani prosedur SICS. ${ }^{11}$

\section{SIMPULAN}

Poor outcome cenderung dialami oleh kelompok dengan katarak senilis matur dibandingkan dengan katarak senilis imatur yaitu dengan proporsi 9,1\%, borderline outcome cenderung dialami oleh kelompok dengan katarak senilis imatur dibandingkan dengan katarak senilis matur yaitu dengan proporsi 23,8\%, dan good outcome cenderung dialami oleh kelompok dengan katarak senilis matur dibandingkan dengan katarak senilis imatur yaitu dengan proporsi $81,8 \%$. Poor outcome cenderung dialami oleh kelompok subjek yang menjalani prosedur SICS dibandingkan dengan phacoemulsification yaitu dengan proporsi $16,7 \%$, borderline outcome cenderung dialami oleh kelompok subjek yang menjalani prosedur phacoemulsification dibandingkan dengan SICS yaitu dengan proporsi 23,1\%, dan good outcome cenderung dialami oleh kelompok yang menjalani prosedur SICS dibandingkan dengan phacoemulsification yaitu dengan proporsi $83,3 \%$.

\section{DAFTAR PUSTAKA}

1. American Academy of Ophthalmology Staff. Lens and Cataract. American Academy of Ophthalmology. 2012;11(1):3-231

2. Pusat Data dan Informasi Kementerian Kesehatan RI Staff. Situasi Gangguan Penglihatan dan Kebutaan. Pusat Data dan Informasi Kementerian Kesehatan RI. 2014. $2-12$ 
3. Abraham A. Age Related or Senile Cataract: Pathology, Mechanism and Management. Austin Journal of Clinical Ophthalmology. 2016. 1-8

4. Ahmad K. Gendered Disparities in Quality of Cataract Surgery in a Marginalised Population in Pakistan: The Karachi Marine Fishing Communities Eye and General Health Survey. Plos One. 2015:1-12

5. ClaudiaG, JonuscheitS. Effectof individual-leveland socioeconomicfactors on long-term survival after cataract surgery over a 30-year period. J Catarct Refact Surg. 2017;43(2):537-542

6. Salomo SR. Prevalence and Outcomes of Cataract Surgery in Brazil: The São Paulo Eye Study. Am J Opthmol. 2009;148:199-206.

7. Sheila KW, Valmadrid CT. Public Health And The Eye. Survey of Ophthalmology. 1995;39:323-334.

8. Husain R. Prevalence of Cataract in Rural Indonesia. American Academy of Ophthalmology. 2005;112:1255-1262.
9. Liu YC. 2017. Seminar Cataracts. The Lancet Journals. 2005;390: 600-612

10. Gogate P. Why Do Phacoemulsification? Manual SmallIncision Cataract Surgery Is Almost as Effective, but Less Expensive. American Academy of Ophthalmology. 2007;114:965-968.

11. Venkatesh R. Phacoemulsification versus manual small-incision cataract surgery for white cataract. J Catarct refact Surg. 2010;36: 1849-1854.

12. Supradnya A, Jayanegara IGN, Sugiana IGNM, Widiana IGR. Phacoemulsification and sutureless large-insicion manual cataract extraction change corneal sensibility. Bali Medical Journal. 2013;2(3):108-112.

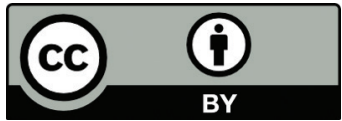

This work is licensed under a Creative Commons Attribution 